\title{
"If I Shut My Eyes, I Cannot Hear You": The Regulation of Parent and Adolescent Communication About Sexual Practices and Identities in the Family Context
}

\author{
by Sharon Elley \\ University of Leeds \\ Sociological Research Online, 15 (2) 4 \\ $<$ http://unw. socresonline.org.uk/15/2/4.htm/ > \\ $10.5153 /$ sro. 2114
}

Received: 23 Nov 2009 Accepted: 17 Mar 2010 Published: 30 Apr 2010

\begin{abstract}
This paper examines parent-adolescent communication about sexuality in the family context. Of central concern is how parents and their adolescent children interact and communicate about sexual identities and practices. The paper focuses on kinship and familial relations between parents and adolescents, family dynamics and the processes impacting on young people's emergent sexual development and informal sex education in the home. The data is drawn from interviews with 38 young people aged 15-21 years with another 31 participating in focus-groups. The paper argues that mutual and open dialogue about sexuality between parents and adolescents remains highly circumscribed due to how sexuality is relational and regulated in the family context. The data reveals that despite strong family relationships, complex patterns of surveillance and negotiation mean that parents and children monitor and control situations related to expressing sexuality. Instead of 'passive' processes operating to manage sexual identities, this paper finds that parents and young people necessarily draw on more sophisticated practices of what can be conceptually termed as the 'active acknowedgement' and 'active avoidance' of sexuality as a means to manage sexual identities across different family contexts.
\end{abstract}

\section{Keywords: Adolescence; Communication; Family Practices; Kinship and Familial Relationships; Intimacy; Parenting; Sex and Relationship Education; Sexuality; Young People}

\section{Introduction}

1.1 Why do so few young people nominate parents as their main source of sex and relationship education? Why do so few young people nominate parents as their main source of sex and relationship education? In the $21^{\text {st }}$ century, sexual mores are confused, contradictory and contested. Living in a media saturated sexualised culture does not necessarily mean that sexual behaviour has become increasingly open (Kehily 2002; Scott and Jackson 2004). Those who can talk about it, where and with whom still remains circumscribed. Childhood and youth are a key formative period in determining young people's developing sexual identities. Research shows the family significantly impacts on children's developing beliefs, attitudes and practices around sexuality, gendered relationships and later sexual behaviours (McDonald and Parke 1986; Walker 2004).

1.2 The family has theoretically been reconceptualised from a static undifferentiated 'nuclear' unit to understanding families and family practices as diverse entities. Rather than an 'ideal' model of what families 'should' be, Morgan (1996: 25) argues it is important to 'examine what actually takes place between individuals within households'. For Giddens (1998) couples and parents strive to successfully achieve what he describes as the 'pure relationship' amongst both romantic partners and parent-child relations based on a 'democratic ideal' of family life. This implies '...equality, mutual respect, autonomy, decision-making through communication....Much the same characteristics also supply a model for parent-child relationships.... but these will be more negotiated and open than before' (Giddens 1998: 93-4). However, as Jamieson (1998: 161) suggests, the pure relationship in the democratization of the family is more constrained around parent-child relationships with status differences compounded by how children never start off as equal to parents. Communication in the area of teenage sexuality remains particularly difficult (Kehily 2002; Allen 2007) and sits in tension with the recent emphasis on parents as sex and relationship educators (hereafter SRE; DoH 2001; 2004). 
1.3 The Social Exclusion Unit's (1999) teenage pregnancy report highlighted the significance of parents supporting children and young people to cope with the development of sexual identity and respectful relationships. Key to this is adults and children working toward overcoming a lack of confidence, discomfort and limitations around discussing sexual matters. However, other research suggests that some aspects of open and mutual dialogue around sexuality remains difficult and contradictory. This is because verbal communication and non-verbal gestures maintain symbolic boundaries around appropriate behaviour which both parents and adolescents are keen to avoid overstepping (Kehily 2002; Allen 2007). In particular, Solomon and colleagues (2002), and Kirkman and colleagues (2005) suggest the constraints of gender, incest taboo, social mores and parental limitations contribute to silencing open communication around sexuality in the home. These analyses, however, imply that parents and children are passively unaware, and ignore, deny or avoid sexual identities. Communication in both speech and action, conversely, has a much more active function. Intimacy in the family and the role parents play in regulating young people's sexual identities remains less well understood, yet, this is crucial to how young people can develop a positive sexual identity and safe sexual practices for themselves.

1.4 This paper considers the internal dynamics and practices within families, exploring how parentadolescent communication and intimate relationships operate to regulate young people's emergent sexual identities. This offers insight into how parents and young people communicate both verbally and non-verbally about sexual identities and sexual matters where every aspect of human life 'breathes a sexual atmosphere without it being possible to identify a single content of consciousness which is 'purely sexual' or 'which is not sexual at all" (Merleau-Ponty 1962: 154). The research explored young people's experiences and values regarding intimate relationships, views on SRE, and family practices and backgrounds. Despite calls for 'open' parent-child communication about sexuality, in what Giddens (1998) describes as 'the pure relationship' in a democratization of family life, this paper highlights the inherent tensions and contradictions in this position (for example, BMRB International 2004; DoH 2004). The data revealed that despite often strong kinship and familial relationships, complex patterns of surveillance and negotiation mean that parents and their adolescent children attempt to monitor and control sex-related situations in various ways. Instead of 'passive' processes which ignore, deny, silence or avoid acknowledging sexual identity, parents and young people think and act in ways better captured by the concepts of 'active acknowledgement' and 'active avoidance'. Sexual identities are found to be mutually avoided and acknowledged in family communication, and in how family members intimately relate to one another in the home. These new insights into how we theorise young people's emergent sexual identities hold significant implications for offering encompassing sexual health messages to young people.

\section{Parent-Adolescent Relationships, Sexual Identities and Open Communication}

2.1 In the UK, high rates of teenage pregnancies and sexually transmitted infections (hereafter STIs) have led to public health measures increasingly focusing on improving young people's sexual health and schoolbased SRE (DfEE 1999, 2000; Social Exclusion Unit, 1999). Recent government initiatives also centre on improved parental participation in children's sexual development and informal sex education (DoH 2001; DfEE 2000). The family significantly contributes to the reproduction of sexualities from birth where the 'impact of parenting is felt throughout one's lifetime and for succeeding generations. No other form of interaction can boast such power and longevity' (Pugh et al. 1994: 1). Few young people, however, nominate their parents as their main source of information about sex and sexuality, with friends, the school and the media being more significant (Wellings et al. 2001; Wight et al. 2006). Most research into parentchild-adolescent practices assumes that open and greater communication and interaction between adolescents and parents is essential and desirable with open discussion about sexuality particularly vital. This fails to acknowledge the contradictory nature of adolescent-parent discussion. Nevertheless, children and young people still express a desire to talk to their parents about sexual issues, while parents continually seek further guidance in this area (Balding 1999; Wight et al. 2006), and positive and negative parent-child communication about sexuality has been found to significantly impact on children and adolescents sexual behaviours.

2.2 Despite the family's essential role in socialising children into sexually appropriate behaviour, all family members find communicating about sexuality difficult (Kirkman et al. 2005). Research shows that the effectiveness of parental interaction and communication about sex varies resulting in a range of sexual health outcomes for young people. Parental monitoring (Huebner \& Howell 2003), adult supervision (Cohen et al. 2002), parental trust (Borawski et al. 2003), parental support and connectedness with children (Chwening \& Koningsfeld 1998) have all been associated with less sexual risk-taking and delayed intercourse. Parent-child communication about sexual issues, contraception and parent portrayals of sex as positive has also been linked to increased contraception use (Stone \& Ingham 2002; Wellings et al. 2001), delayed sexual experience and fewer sexual partners (Johnson et al. 1994). Alternatively, the effects of negative parenting have been related to increased levels of sexual activity amongst boys (Feldman \& Brown 1993) and a lack of child-parent communication about sex has been associated with higher teenage 
pregnancies (Wellings et al. 2001). Research suggests that parent-child communication about sex and sexual activity can range from open dialogue to an unwillingness to discuss sexual matters due to many factors.

2.3 Questions of parent-adolescent communication about sexuality often focus on the social constraints and sanctions which influence and limit discussions. Children and young people find discussions embarrassing (Buston et al. 2002), fear parental objections to sexual activity or negative parental assumptions if they broach the subject (Holland et al. 1998; West 1999). Similarly, parents' lack of awareness, confidence and embarrassment (Walker 2001; Walker 2004) makes sex a difficult topic to discuss. Numerous studies show that the biological sex or gender of parents and children matters with mothers usually being the main sex educators (Walker 2004), greater difficulties experienced in discussions with sons (Sharpe et al. 1996) and less parental worry about son's sexual activity (Aggleton et al. 1998; Hughes et al. 1999). Other studies show that children prefer to talk to same-gender parents (Kirkman et al. 2005; Wight 1994), and both parents and children have limited communication skills around sexuality (Walker 2001). Rosenthal and colleagues (1998), for example, offer five parental communication styles: avoidant, reactive, opportunistic, child-initiated and mutually interactive. These styles varied based on who initiated the communication, the level of comfort of mother and adolescent; and, the frequency, context and topics discussed or avoided. Much of this research, however, implicitly assumes that increased open communication and interaction between adolescents and parents is desirable rather than considering its contradictory nature.

2.4 Research into parental-child interaction and communication consistently presumes that openness in family communication is essential for developing social, emotional and practical coping skills in adolescents (Noller \& Callan 1990). 'Functional' families have open communication styles (Barnes \& Olson 1985 ) which has been associated with lower adolescent sexual risk-taking (Kotchick et al. 1999). However, as Kirkman and colleagues (2005) suggest, numerous constraints apply to open communication in such a sensitive area with the concept of 'openness' encompassing a range of interpretations. Their empirical data revealed openness in families had an important and contradictory nature. Whilst openness formed the basis of all good family communication about sexuality, and meant answering questions and being open-minded, this was balanced with a need for privacy and open communication as constrained by gender, sexual taboos, social mores as well as parental limitations. Similarly, Solomon and colleagues (2002) show how young people resist parental control by withholding or threatening to withhold personal information in an attempt to develop their adult identities, independence and a sense of agency away from their families. For parents, gaining sexual information means retaining power and control whereas withholding information from parents ensures adolescents privacy and power (Solomon et al. 2002). These contradictory goals point to tensions in the concept of open communication about sexuality and sexual behaviour.

2.5 Research around parent-child and adolescent communications about sexuality and sexual behaviour assumes that the frequent 'silence', 'ignorance', 'denial' and 'avoidance' of adolescent sexuality has a mostly negative influence on young people's emergent sexual identities which can, and should, be addressed. Most research which acknowledges the complex and contradictory nature of silent communication about sexuality (see West 1999; Kirkman et al. 2005; Solomon et al. 2002) still presents this as a passive process which occurs to maintain boundary management between parents and adolescents, or struggles over identities, and favours open dialogue of mutual disclosure between parentchild (West 1999; Walker 2004). Instead, this paper argues that communications and expressions of sexual identity are a much more complex process than these ideas encapsulate. It shall be argued that parents and young people draw on intricate processes of what I have conceptually termed 'active avoidance' and 'active acknowledgement' or a combination of both simultaneously as a means to manage the expression of sexual identity and practices. I suggest greater attention should be given to how and why these processes operate in order to provide better SRE rather than focusing on overcoming parental-child limitations. Processes of actively avoiding and acknowledging sexuality enables family interaction, communication and young people to develop sexual identities for themselves. In the process, family cohesion is maintained, conflict avoided and young people are empowered to make autonomous decisions. This paper concludes with some suggestions for possible ways forward which may strengthen parental involvement in SRE while still recognising a need to give adolescents the space to articulate their concerns and achieve their sexual identities free from parental intervention.

\section{The Study and Participants}

3.1 In this research, 14 young women and 21 young men aged between $15-21$ years participated in one-toone interviews, and 21 women and 10 men engaged in focus group discussions. Of interest were the ways in which young people communicate about sexuality and sexual practices with parents, whether parents were cited as good sources of SRE, and how young people's emergent sexual identities were recognised and managed by parents and children. The research was conducted in a relatively small local Authority in 
the North East of England from September 2006-7, and drew on a qualitative framework using a multimethod approach which included a diverse sample group.

3.2 In this research, 14 young women and 21 young men aged between 15-21 years participated in one-toone interviews, and 21 women and 10 men engaged in focus group discussions. Of these, 31 participants were aged 15-16; 26 were aged 17-18; and, 12 were aged 19-21 years old. The larger concentration of participants in younger age categories was due to them being contacted and interviewed in youth centres. Semi-structured interviews lasted approximately twenty to ninety minutes, were recorded via a Dictaphone and transcribed verbatim. The sampling framework was 'opportunistic' and became more strategic so as to include a range of characteristics and backgrounds. Class categorisations of working, intermediate and middle-class were employed as a means of conveying degrees of class positioning and were based on young people's judgements of their own class positions, parental occupation and level of education, family background, social networks and geographical location. These were theorised in conjunction with family dynamics, linking young people with their social context and interactions denoted by complex patterns of support, dependence and obligation within the family (Irwin 1995).

3.3 The participants experienced a wide range of kinship and familial arrangements and compositions. Of the 69 young people, 11 aged 18-21 lived independently from parents; 39 lived with both birth parents, 13 lived with step-parents and 7 with lone parents. The meaning given to family is an indication of the different forms of intimacy, relating in different contexts and the kinds of support which young people can access. I have attempted to articulate complex intimate interactions through a framework of harmonious and inharmonious family ties and contexts. This was generated to impose structure on emerging themes and patterns so as to permit analysis of family interactions which generally fell into two broad descriptions of family life. Some young people described harmonious family relationships based upon openness, trust and mutual respect. Other young people depicted inharmonious parent-child relationships characterised by difficulties, disruption and tension in the home often leading to independent living. Obviously, there are commonalties between the two and this is a rudimentary form of organising the diversity of human action which risks losing the complexity of these young people's lives behind simple classifications. The quality of family ties in this research was usually testimony to the openness of communication in the home and the narratives presented here are, therefore, from those young people who described kinship and familial relationships as mostly harmonious. This is because the young people who described tense and inharmonious relationships with parents claimed they could not discuss 'anything with parents' let alone matters of a personal nature. The starting point for this research then is to compare similar relationships across different contexts rather than positive with negative relationships as other research in this area. Family communication in the home was theorised in relation to young people's emerging sexual identities with some young people describing themselves as sexually active while other young people were inactive.

3.4 Sexuality and gender are difficult concepts to separate out leading to debates about whether it is theoretically useful or whether to prioritise gender over sexuality or emphasise the institution of heterosexuality (see Richardson 1996; Jackson 2003). I make no attempt to disconnect these dimensions here and young people's emerging sexuality refers to sexual identities and gendered practices in their various historical and cultural forms. Powerful discourses of 'heteronormativity' (Holland et al. 1998) and Rich's (1983) 'compulsory heterosexuality' inform young people's sexual identities with heterosexual attraction often 'assumed' to be the only 'natural' form of sexuality. All of the sample group identified as heterosexual with the exception of 3 young women who identified as bisexual. Participants chose to describe heterosexual relationships during interview with the exception of one woman who briefly mentioned same-sex attraction. Hence, this paper focuses on 'heterosexual' practices and identities rather than including a spectrum of sexualities. Of the young people who described themselves as 'sexually active' (engaged in sexual intercourse) 29 had first sex before aged 16. The issue of underage sex does not, however, appear to impact on the results in a significant way. This may be because the focus of the research was on communication in the home around sexuality and related practices more generally as opposed to actual intercourse which may have legal implications, hence, affect parent-child communication. Age-related discussions between parents and adolescents paid little attention to the legalities of under-age sex with more concern expressed about levels of maturity and experience.

3.5 Discussing sexual activity and intimate matters with young people meant a careful consideration of the ethical implications of the research on the participants. In the spirit of giving 'voice' to young people and recognising them as 'expert witnesses' on their own lives, consent to participate in this research was arranged with the young people themselves without parental agreement. I positioned myself within the institutional practices of the Youth Service (parental consent is not necessary for age 14 upwards) with consent an ongoing process of (re)negotiation throughout the interview. Similarly, multi-methods were purposely chosen such as focus-groups intended to minimise embarrassment and provide social support in the context of 'threatening' topics and one-to-one interviews which facilitated the exploration of more personal information. Young people were not invited to reveal overly intimate information which they may 
later regret and interviews were cut short if young people appeared uncomfortable or distressed which happened on two occasions. Linked to this, confidentiality was guaranteed unless participants disclosed evidence of harm or abuse which was then passed onto the Youth Service staff. Every effort was made to reduce the power dynamics between researcher and participants' through enabling conversation and encouraging the participants to control and direct interviews through collaborative practices. This included avoiding assumptions and 'normalising' certain behaviours, for instance, of heterosexuality or sexual activity. Overall, participants indicated they enjoyed the research experience and appreciated the opportunity to share their views and discuss personal matters.

3.6 I now turn to the empirical data to illustrate that across diverse family relations, social situations and parent-child communication about sexuality are actively managed and controlled in various ways. This also has relevance for understanding why SRE discussions in the family context remain challenging.

\section{Parent's and Adolescent's Management of Sexual Identities}

4.1 Routine socially sanctioned family practices regulate the expression of young people's emerging sexual identities. Research indicates, however, that the family often offers young people contradictory meanings about sexuality. Echoing West's (1999) research, few young people across this research found discussing sexuality with either parent straightforward despite good relationships and the ability to openly communicate. The data here revealed that the majority of young people described parent-child relationships based upon openness and disclosure; mutual respect and good relationships which enabled dialogue about sexual matters. However, discussions about sex and expressions of sexual identity also ran counter to gender constraints and social norms (Solomon et al. 2002; Kirkman et al. 2005). Regardless of the condition of parent-child relationships, both parents and young people invest in a complex weave of mutual 'active acknowledgement' and 'active avoidance' about aspects of sexuality both consciously and subconsciously across different family contexts.

\section{The Active Acknowledgement of Sexuality}

4.2 The young people in this research indicated that talking to parents about 'anything' was the most important aspect of good relations and communication which enabled dialogue around sexuality and sexual behaviour. Other valued characteristics included acknowledging a young person's growing 'independence' and trusting them to make sensible decisions and act responsibly, although still recognising a need for sporadic parental support (see Solomon et al. 2002; Kirkman et al. 2005). Communication between parent and child was ideally based upon 'honesty' and 'trust' from parents, echoing other research (Solomon et al. 2002; Kirkman et al. 2005). Unprompted, several young people in this research described the best childparent relationships as holding 'friend-like' status. This meant an open and trusting relationship which was modelled on the friendship bond and conveyed adult-like status which should, in theory, enable dialogue around sexuality. Even in this type of relationship, however, it was rare that a young person discussed personal matters of a sexual nature.

4.3 On the rare occasions when sexuality and sexual behaviours were acknowledged, there was evidence that communication always remained partial and limited. The following extract from Bonny illustrated those rare instances when sexuality was 'actively acknowledged'. Bonny had no contact with her father and described herself as having a close friendship-like relationship with her mother which appeared to enable intimate discussions. Bonny's mother appeared to acknowledge and contribute towards managing her adolescent child's sexuality in pragmatic ways. This seemed to be testimony to the strength of their relationship:

\section{Sharon: So what about your mum?}

Bonny: Yeah we're like best-friends I mean she's in her forties but she still acts like a teenager.

Sharon: And you can talk to her about sex...?

Bonny: I did [feel embarrassed] when we first started talking about it but now we can talk about anything....My mum gave me the idea of going to get the injection cos it's like she has to remind me some mornings to have it because I'm...late for school...she's like "have you taken your pill"... (fifteen, working-class, harmonious relationship with mother and sexually active).

4.4 Some young people referred to their parent's 'active acknowledgement' about sexual issues as an indicator of caring and closeness in the relationship. As an extension of the parental role, some parents can be seen to contribute to regulating and controlling their children's emerging sexualities and behaviours 
through careful monitoring. Complex patterns of surveillance and negotiation emerged, however, which indicated that parents and children attempted to monitor and control situations in various ways -sometimes through one parent 'actively acknowledging' their children's sexuality with the other parent 'actively avoiding 'sexual identities and behaviours.

4.5 Often young people could only talk to one parent about sexual issues or neither parent. The following extract from Kelly demonstrates close kinship/familial relationships where she spontaneously described her family relationships as being friend-like. Despite this, Kelly suggested she would be unable to communicate to her mother if she was sexually active, although she would be able to discuss this with her father:

Kelly: My mum....we're quite good friends...

Sharon: Do you get on with your dad?

Kelly: ...I don't see him as a dad, I see him as a friend because he doesn't treat me like a daughter really... [...]

Sharon: When is it seen to be acceptable to have sex?

Kelly: My parents would say sixteen but if I was having sex when I'm sixteen I still wouldn't tell my mum cos she'd flip, I don't know... because my dad said "you can have sex now, I don't care as long as you do it safely" and my mum's like "just don't get involved yet cos your not like virtually grown up yet to do it"... [but] I wouldn't tell my mum that I was doing it unless worse came to worse... (fifteen, middle-class, harmonious relationship with parents and stepfather, and sexually inactive).

4.6 Some young people indicated they were more able to discuss sexual matters with one parent of the opposite gender rather than the same-gender parent. Discussing sexual matters between fathers and daughter, although rare, were taken by young people as representing a greater closeness between parent and child despite running counter to gender role expectations and sanctions. However, the reasons for being unable to talk to the other parent were far-reaching. These ranged from perceived parental limitations around dealing with sensitive issues, parents' perceptions of children's maturity, as well as notions of conforming to parental expectations, avoiding conflict around adolescents' growing independence and autonomy, and, in some cases, children protecting their parents from being forced to acknowledge their sexuality. Even within kinship relations described as 'friend-like' it was rare that young people were able to discuss many aspects of sexual identity and sexual behaviour. In Bonny's case where her sexuality was 'actively acknowledged' by her mother, complex patterns of acceptance, negotiation and management of her daughter's sexuality appeared to operate in how her mother acknowledged her sexual activity and reminds Bonnie to take precautions. Despite being legally under the age of consent to sex, Bonny and her mother had agreed to discuss contraception and becoming sexually active when the time was right for Bonny. In contrast, Kelly's father accepted her emerging sexuality whereas Kelly's mother viewed her as not mature enough to consent to sex which led to Kelly's desire to avoid communication and conflict in this area.

4.7 Despite good parent-child relationships with open channels of communication and democratic parenting styles (Giddens 1998; Jamieson 1998), matters of a sexual nature were still to some extent 'actively avoided' in various ways. This occurs through both verbal and nonverbal social cues and sanctions. Even though Bonny's mother colluded in her use of contraception (as seen above) Bonny kept a pregnancy scare and her bi-sexuality private. On both accounts, Bonny felt she would of needlessly upset her mother and would have only approached her if she was pregnant or in a serious relationship with another woman. So, regardless of the quality of the relationship, young people's sexual development partly remains isolated and unacknowledged.

\section{The Active Avoidance of Sexuality}

4.8 Most young people across this research indicated an inability to discuss sexual matters with parents despite describing harmonious relationships. To varying degrees, these young people 'actively avoided' revealing aspects of their sexual identities to parents. This was captured in Ellie's description of a very good relationship with her parents who attempted to give her the 'best in life'. However, when it came to sexual matters, she presented a side of herself which her parents would find 'appropriate' and 'acceptable' so much so that her parents were unaware she had 'even kissed a boy'. Respect for her parents and a desire to not disappoint them featured heavily throughout her narrative and presentation of herself as non-sexual: 
wanted them to see me as daddies little girl and l'd like to keep it that way cos we have like a relationship where like my mum's very old fashioned...she says she is and she admits she is and my dad doesn't really talk to me... if you say sex he goes bright red, they don't like discussing it and I don't want to make them like feel uncomfortable and me at the same time so... [...]...I just can't, I don't want my parents to see this other side of me cos no matter what I do wrong in their eyes, l'll always be sort of decent...l'd like to keep it as their little girl for the meantime (fifteen, middle-class, harmonious relationships with parents and sexually inactive).

4.9 Despite being 'open' with other people, parental expectations and limitations intertwined with Ellie's desire to protect her parents from her budding sexuality and an uncomfortable situation. Simultaneously, her parents positioned her as innocent and child-like which she then reinforced to maintain their approval and acceptance. The avoidance of young people's emerging sexualities was also evident in how parents and young people managed social situations through actions as well as speech. The following extract from Ronnie shows both his own and his mother's deliberate active avoidance of sexuality. Ronnie had a close relationship with his mother and brother since his father had passed away. While he talked to his brother about 'some things' he described how his mother made noises such as banging kitchen cupboard doors to let him know she had arrived home late at night:

I couldn't, my mum always tried to get me to, saying stuff to me but l'd rather just [talk to brother]...my mum knows, well thinks I do anyway, have sex a lot because my girlfriends always around at my house and my mum, she won't even come up the stairs when we're there in case she catches us doing anything because my mum she's shy like that...she'd be too embarrassed so she just like stays out of the way... (fifteen, working-class, harmonious relationship with mother and sexually active).

4.10 Forms of embarrassment entwine with gender sanctions and a desire to protect his mother from his own sexual activity through both verbal and non-verbal gestures designed to socially manage interaction and regulate sexuality within particular boundaries. Like Ellie's parents above, his mother showed limitations in communicating about sexual matters with a preference for actively avoiding situations which may bring sexual issues to the forefront. Again, similar to Ellie, Ronnie attempted to protect his mother from confronting his sexuality through censoring any 'real' acknowledgment of his sexual activities. Hence, young people's narratives revealed a very genuine parent-child avoidance of one another's 'real' lives and sexual identities. Across the research, few young people expressed a desire to discuss matters with parents beyond basic biology or as Lenskyi (1990) aptly says, 'plumbing and prevention'. Indeed, some young people described how their parents preferred to avoid knowing too much about their children's sexual activity and the young person took this to indicate parental acceptance of their growing maturity and independence.

4.11 Some participants described how their parents 'interfered' in their lives in an attempt to monitor and control their children's actions. Linked to sexuality, some young people used this to re-assert their growing independence free from parental restrictions and, sometimes, provoke parental anger. Such young people raised notions of agency set against issues of control with sexuality providing a vehicle to adulthood. As Solomon and colleagues (2002) claim, relationships between parents and adolescents are often characterised by a renegotiation of control over the young person's life at particular age stages which includes issues of choice, identity and independence. Due to young people's transitional status, they lack power and control over their lives and their own sexuality was one of the few places they reasserted authority. The following extract from Jay demonstrated his desire to form his own personality free from parental expectations and control, sometimes using his sexuality against his parents:

Sharon: So what does a close relationship mean to you?

Jay: .......find with my parents...it's like: "you just don't fit in with us anymore" and it's "well I'm growing up, I am my own person, I aren't meant to fit in with you" that's the whole idea of becoming someone different, you're forming your own identity, it's like my mum was...like: "you don't dress how you used to anymore"... she just disagrees with what I am perhaps growing up like... parents always have preconceptions of what their children are going to be.... ...they don't see the me that everybody else sees... I am a different person to what I am at home because I don't feel I can express things...

4.12 Linked to sexuality:

Sharon: So can you talk to your parents about sex and relationships and that type of thing?

Jay: My mum more so than my dad but I know if I felt I needed to I could but it's not 
something we sit and generally chat about...I am not bothered about... [condoms] I would always carry one with me...I find it quite humorous when my mum seems to come across them (both laugh) "what you got these for?" "because I'm sixteen, I'm male" which she doesn't take too lightly but at the same time I think I should keep myself safe not because it doesn't impress my parents but it throws a nice little dig in as well...

Sharon: Does your mum not try and have that conversation with you?

Jay: No, actually, actually she just basically prefers, I think she was actually quite pleased to see the fact that even if I'm not in a sexual relationship I am keeping contraception...she just usually takes some comedian side on it and gets some kind of backlash that makes her look stupid, it's, I don't think she's got anything against it (sixteen, middle-class, harmonious relationship with parents and sexually active).

4.13 Establishing one's own identity distinct from the family is seen as a key process of 'youth' (Jamieson 1998). Some young people indicated that their parents struggled to acknowledge their children's developing maturity, independence and making choices of their own outside the family. Disclosing sexual information risks losing control over their personal lives and family support. Some young people, therefore, actively avoided communicating too much about themselves and their personal lives at the expense of intimacy, paralleling evidence from Jamieson (1998), and Solomon and colleagues (2002) research. On other occasions, these young people used their sexual identities as a source of conflict against their parents to reassert authority over their lives. Other young people in this research described strategies of mutual 'active avoidance' where parents and young people mutually avoided one another's sexual identities in various ways.

\section{Mutual Active Avoidance of Sexuality}

4.14 The lack of open dialogue around sexual issues also meant that parents' sexual identities were 'actively avoided' by their children, or both parties practiced mutual avoidance. This form of unacknowledged adult sexuality was captured during a focus-group interview with Karen who generally experienced a very good relationship with both parents but, in particular, only really discussed sexual matters with her father. Karen described her relationship with her father as: '...l'm a daddy's girl all the way but my dad is one of the best...I can talk to my dad about anything...' Consequently, Karen described her mother as: 'really, really quite strict' about sexual matters and disclosed how her mother stated: 'I'm disappointed in you' at finding condoms in Karen's jeans pocket. Karen explained that her mother actively avoided sexual issues through 'pretence':

My mother doesn't do sex talks, she doesn't do sex full-stop, it doesn't happen...it doesn't get mentioned...ever...she lives in this little bubble (seventeen, at college, middle-class, harmonious relationship with parents and sexually active).

4.15 Karen further explained this was due to her mother's 'unrealistic' future expectations and assumptions around young people's behaviours:

My mum was like..."I don't want you going down that road"...cos my mum has this idea that you're either perfect, a virgin, don't drink, don't smoke, don't do drugs, don't have friends, don't go out, you do everything perfect, and you go to college, go to university and that's how it all goes or you do drugs, you do sex, and you don't go to college and you end up like a Chav and it's like...my mum can't understand that some people that go to university do smoke, and...just might have sex...she wants me to be a 40 year old virgin...yeah, out the window!

4.16 Karen further explained that it was her father who first opened up dialogue around sexual matters and also made reference to her mother's sexuality. The next extract showed how parent and child mutually 'actively avoid' acknowledging some aspects of sexuality:

My dad...when he gave me the sex talk, first of all he was drunk...and he said: "sex is a good thing, enjoy it and my mother was an animal"... [all laugh] and I was like: "DAD, NO!"

4.17 Openness and privacy need to be balanced (Kirkman et al. 2005) and disclosing personal information is not the same as revealing intimate sexual details. Still, the recognition of his daughter's 'right' to enjoy her own sexuality had perhaps contributed to Karen's sense of her own entitlement to sexual pleasure and desire which was threaded throughout her narrative. As Allen (2007) suggests, young people with positive and legitimate sexualities can better act in ways which support their sexual well-being than those who believe expressions of sexuality are inherently 'wrong'. Karen's statement also illustrated how parents not 
only 'actively avoid' sexuality but adolescents too find it difficult to communicate about parents sexual identities. Generally, avoiding parental and adolescent sexual desire was evident across all young people's narratives. The final extract from Kirk illustrated the actions young people engage in as an attempt to avoid acknowledging some aspects of sexuality and maintaining privacy balanced with openness:

\begin{abstract}
... when there's films on about sex and that I don't like watching it with my mum, I go out, pretend I need something to eat till it's finished...it's like watching, well it's not as bad but it's like watching porn movies with your mum, not as bad but it is sort of, I don't like it so I go and get something to eat or something (fifteen, working-class, harmonious relationship with parents and sexually inactive).
\end{abstract}

4.18 The intrusion of sexuality into the parent-child relationship means that some aspects of sexuality, and particularly sexual desire, are necessarily actively avoided through various strategies to manage social situations. Other reasons for the active avoidance of sexuality, however, also existed across young people's narratives, including those whose sexuality was 'actively acknowledged' in various ways. An adolescent's emergent sexuality is relational and develops across different significant relations and sources outside of parental knowledge. However, sexuality has a privileged point of development in the family. Family practices and relationships control and manage the sexual expression of adults and adolescents through degrees of active acknowledgement and active avoidance seen in forms of speech and action. Central to this is the need for greater opportunities to communicate about sexual matters to be balanced with a recognition that some aspects of sexual identity will, and should, remain autonomous and somewhat actively silenced.

\title{
Conclusion
}

5.1 This paper has explored the complexity of young people's kinship and familial relationships, family practices, and how these relate to expressing and communicating about sexual identities and practices. Most of these young people described harmonious family relationships associated with openness, honesty and trust. However, there remained a tension about expressing sexuality which ran across all young people's accounts rendering the acknowledgement of adolescent sexual identities as somewhat partial and incomplete. This suggests that young people's emergent sexual identities are socially managed through degrees of 'active acknowledgement' and 'active avoidance' or mutual and simultaneous processes. Understanding these processes is significant because of the recent emphasis on greater parental involvement in educating children about sexuality. These practices of sexual identity management are often theorised as passive processes of silence, denial or ignorance. This paper, however, argues that they are sophisticated 'active' processes necessary to enable and regulate social interaction and communication across different family contexts. Adolescent sexual identity is produced at the intersection of the child as 'sexually innocent', the young person who should practice safe sex (Allen 2007) and the child-adolescent who should be protected from sexuality including predatory adults. It follows that there is a disjunction between relative silences and the quest for intimate knowledge about sexual matters and a developing adolescent sexual identity (Allen 2007). Paradoxically, this is at a particularly crucial time when adolescent sexuality is experienced as ambivalent and presumed to be partly formed and in transition.

5.2 The young people in this research indicated that parents are not necessarily the best source of SRE particularly around sexual activity and personal issues. Parents who invest both personally and financially in their children can be unwilling to recognise their children as developing sexual individuals (Solomon et al. 2002) which may affect the nature of the parent-adolescent relationship. In critically exploring parentadolescent communication about sexuality and sexual activity, this paper is not suggesting there is an 'ideal' style of 'good parenting' for educating and communicating with young people. Instead, it acknowledges that there are various strategies that parents can employ to support their children's sexual development including actively acknowledging and avoiding various social situations and behaviours in the face of adolescent sex. A combination of formal and informal SRE has been highlighted as responsible for the lowest rates of teenage pregnancy in Scandinavian countries (Aggleton et al. 1998) and demonstrates that families have a vital role to play in SRE. As sexuality is relational and developed through a number of social relations and interactions, several sources outside the family also have a crucial role in supporting adolescent sexual development. Therefore, an eclectic view of SRE provision offering young people access to numerous sources of information and support across a range of contexts should enable adolescents to seek appropriate sexual health advice. To empower young people to claim a positive sexual identity for themselves also means recognising how practices of active acknowledgment and active avoidance around sexuality seem necessary and crucial to enabling human interaction and intimacy to exist between parentchild-adolescent, as well as across other intimate relations.

\section{Acknowledgements}

I would like to thank Sarah Irwin and James Rhodes for their comments on earlier drafts, as well as the 


\section{References}

AGGLETON, P., OLIVER, C. and RIVERS, K. (1998) Reducing the Rate of Teenage Conceptions. The Implications of Research into Young people, Sex, Sexuality and Relationships, London: Thomas Coram Research Unit.

ALLEN, L. (2007) 'Denying the Sexual Subject: Schools' Regulation of Student Sexuality'. British Educational Research Journal, Vol. 33, No. 2, pp. 221-234. [doi:10.1080/01411920701208282]

BALDING, J. (1999) Young People in 1998, University of Exeter, Schools Health Education Unit.

BARNES, H.L. and OLSON, D.H. (1985) 'Parent-Adolescent Communication and the Circumplex Model', Child Development, Vol. 56, No. 2, pp. 437-447. [doi:10.2307/1129732]

BMRB INTERNATIONAL (2004) Evaluation of the Teenage Pregnancy Strategy, London: British Market Research Bureau International.

BORAWSKI, E.A, IVERS-LANDIS, C.E., LOVEGREEN, L.D, and TRAPL, E.S. (2003) 'Parental Monitoring, Negotiated Unsupervised Time, and Parental Trust: The Role of Perceived Parenting Practices in Adolescent Health Risk Behaviours', Journal of Adolescent Health , Vol. 33, No. 22, pp. 60-70. [doi:10.1016/S1054139X(03)00100-9]

BUSTON, K. WIGHT, D. and HART, G. (2002) 'Inside the Sex Education Classroom: The Importance of Context in Engaging Pupils', Culture Sexuality, Vol. 4, No.3, pp. 371- 335.

COHEN, D.A., FARLEY, T.A, TAYLOR, S.N, MARTIN, D.H, and SCHUSTER, M.A. (2002) 'When and Where do Youths have Sex? The Potential Role of Adult Supervision', Paediatrics, Vol. 110, No. 6, 1-6.

[doi:10.1542/peds.110.6.e66]

CHWENING, B., and KONINGSFELD, R.V. (1998) 'Predicting Adolescents initiation of Intercourse and Contraceptive Use', Journal of Applied Social Psychology , Vol. 28, No. 14, 1245-1285. [doi:10.1111/j.15591816.1998.tb01676.x]

DEPARTMENT FOR EDUCATION AND EMPLOYMENT (1999) National Healthy School Standard, Nottingham: DfEE

DEPARTMENT FOR EDUCATION AND EMPLOYMENT (2000) Sex and Relationship Education Guidance. Nottingham: DfEE.

DEPARTMENT OF HEALTH (1999) Saving Lives: Our Healthier Nation , London: HMSO

DEPARTMENT OF HEALTH (2001) The National Strategy for Sexual Health and HIV . London: The Stationary Office.

DEPARTMENT OF HEALTH (2004) Teenage Pregnancy Strategy Progress Report.

$<$ http:www.info.doh.gove.uk/tpu/tpu.nsf> [accessed 01.12.07].

FELDMAN, S. and BROWN, N. (1993) 'Family Influences on Adolescent Male Sexuality: The Mediational Role of Self-Restraint', Social Development, Vol. 2, No.1, 15-35. [doi:10.1111/j.1467-9507.1993.tb00002.x]

GIDDENS, A. (1998) The Third Way. Cambridge: Polity.

HOLLAND, J., RAMAZANOGLU, C., SHARPE, S. AND THOMPSON, R. (1998). The Male the Male in the Head: Young People, Heterosexuality and Power. London: Tufnell Press.

HUEBNER, A.J., and HOWELL, L.W. (2003) 'Examining the Relationship between Adolescent Sexual RiskTaking and Perceptions of Monitoring, Communication and Parenting Styles', Journal of Adolescent Health , Vol. 33, No. 2, 71-78. [doi:10.1016/S1054-139X(03)00141-1]

HUGHES, K., CRAGG, A. and TAYLOR, C. (1999) Reducing the Rate of Teenage Conceptions. Young People's Experiences of Relationships, Sex and Early Parenthood Qualitative Research, London: HEA

IRWIN, S. (1995) Rights of Passage: Social change and the Transition from Youth to Adulthood. London: UCL Press. 
JACKSON, S. (2003) Heterosexuality, Heteronormativity and Gender Hierarchy: Some Reflections on Recent Debates. London: Routledge.

JACKSON, S. and SCOTT, S. (2004) 'Sexual Antinomies in Late Modernity', Sexualities, Vol. 7, No.2, pp. 233-248. [doi:10.1177/1363460704042166]

JAMIESON, L. (1998) Intimacy: Personal Relationships in Modern Societies. Cambridge: Polity.

JOHNSON, A. WADSWORTH, J. WELLINGS, K. and FIELD, J. (editors.1994) Sexual Attitudes and Lifestyles. London: Blackwell.

KEHILY, M. (2002) Sexuality, Gender and Schooling: Shifting Agendas in Social Learning . London: Routledge.

KOTCHICK, B.A., DORSEY, S., MILLER, K.S. and FOREHAND, R. (1999) 'Adolescent Sexual Risk-Taking Behaviour in Single-Parent Ethnic Minority Families', Journal of Family Psychology , Vol. 13, No. 1, pp. 93102. [doi:10.1037/0893-3200.13.1.93]

LENSKYI, H. (1990) 'Beyond Plumbing and Prevention: Feminist Approaches to Sex Education'. Gender and Education, Vol. 2, No. 2, pp. 217-30. [doi:10.1080/0954025900020206]

KEHILY, M. (2002) Sexuality, Gender and Schooling: Shifting Agendas in Social Learning . London: Routledge.

KIRKMAN, M. ROSENTHAL, D.A. and FELDMAN, S.S. (2005) 'Being Open with your Mouth Shut: the Meaning of 'Openness' in Family Communication about Sexuality', Sex Education, Vol. 5, No.1, pp. 49-66.

MCDONALD, K. and PARKE, R.D. (1986) 'Parent-Child Physical Play', Sex Roles, Vol. 15, No. 7-7, pp. 367-78.

MERLEAU-PONTY, M. (1962) Phenomenology of Perception, (New York: The Humanities Press.

MORGAN, D. (1996) Family Connections: an Introduction to Family Studies, Oxford: Polity.

NOLLER, P., and CALLAN, V.J. (1990) 'Adolescents Perceptions of the Nature of their Communications with Parents', Journal of Youth and Adolescence , Vol. 19, No. 4, pp. 349-62. [doi:10.1007/BF01537077]

PUGH, G. DE'ATH, E. and SMITH, C. (1994) Confident Parents, Confident Children. Policy and Practice in Parent Education and Support, London: National Children's Bureau.

RICH, A. (1983). Compulsory Heterosexuality and Lesbian Existence Only, London: Women Press.

RICHARDSON, D. (ed.1996) Theorising Heterosexuality. Buckingham: OUP.

ROSENTHAL, D.A. and FELDMAN, S.S. (1999) 'The Importance of Importance: The Differentiated Nature of Parent-Adolescent Communication about Sexuality', Journal of Adolescence, Vol. 22, No. 2, pp. 835-852. [doi:10.1006/jado.1999.0279]

SHARPE, S., MAUTHNER, M. FRANCE-DAWSON, M. (editors. 1996) Family Health: A Literature Review. Family Health Research Reports. London: HEA.

SOCIAL EXCLUSION UNIT (1999) Teenage Pregnancy. CM.4342.

<http://www.cabinetoffice.gov.uk/social_exclusion_task_force>

SOLOMON, Y. WARIN, J. LEWIS, C. and LANGFORD, W. (2002) 'Intimate Talk between Parents and their Teenage Children: Democratic Openness or Covert Control', Sociology, Vol. 36, No.4, pp 965-83.

STONE, N., and INGHAM, R. (2002) 'Factors Affecting British Teenagers' Contraceptive Use at First Intercourse: The Importance of Partner Communication', Perspectives on Sexual and Reproductive Health, Vol. 34, No. 4, pp. 191-197. [doi:10.2307/3097729]

WALKER, J.L (2001) 'A Qualitative Study of Parents' Experiences' of Providing Sex Education for their Children: The Implications for Health Education', Health Education Journal, Vol. 60, No. 2, pp. 132-146. [doi:10.1177/001789690106000205]

WALKER, J. (2004). 'Parents and Sex Education: Looking Beyond the Birds and Bees', Sex Education, Vol. 4, No.3 pp. 239-54. [doi:10.1080/1468181042000243330] 
WELLINGS, K., NANCHANAL, K., MACDOWELL, W., MCMANUS, S., ERENS, B., MERCER, C.H., JOHNSON, A.M., COPAS, A.J., KOROVESSI, C., FENTON, K.A. and FIEL, J. (2001) 'Sexual Behaviour in Britain: Early Heterosexual Experience', The Lancet, 358, 1843-1850. [doi:10.1016/S0140-6736(01)068854]

WEST, J. (1999) '(Not) Talking about Sex: Youth Identity and Sexuality', The Sociological Review, Vol. 47, No. 3, pp. 525-547. [doi:10.1111/1467-954X00183]

WIGHT, D. (1994) 'Boys Thoughts and Talk about Sex in a Working Class Locality of Glasgow'. Sociological Review, Vol. 42, No. 4, pp. 703-37.

WIGHT, D. WILLIAMSON, L. and HENDERSON, M. (2006) 'Parental Influences on Young People's Sexual Behaviour: A Longitudinal Analysis', Journal of Adolescence, Vol. 29, No. 4, pp. 473-494.

[doi:10.1016/j.adolescence.2005.08.007] 